
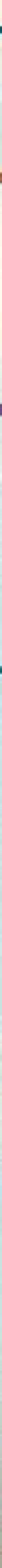


\title{
Conquistas e desafios das pesquisas com Células-Tronco no Brasil
}

\author{
Conquests and challenges of stem cells \\ research in Brozil
}

\author{
Liliana Acero • \\ Diogo Antunes
}

\begin{abstract}
Resumo
O artigo apresenta os principais resultados obtidos da realização de um seminário que tratou das tendências econômicas e sociais nas pesquisas com células-tronco no Brasil e no mundo, bem como das relações entre ciência, sociedade, regulação, ética e políticas públicas. O seminário reuniu representantes da ciência, da academia, da regulação e da sociedade civil. Foram enumerados e discutidos os principais desafios éticos e de saúde pública na governança e na formação das instituições que possibilitem a translação dos resultados dessas pesquisas em terapias clínicas.
\end{abstract}

Palavras-chave: Pesquisas com Células-Tronco, Ciência e Sociedade, Governança.

\begin{abstract}
This paper presents the main results of a seminar that dealt with ongoing socio-economic trends in stem cell research in Brazil and worldwide, as well as with the main relationships established between science, society, regulation, ethics and public policy in this field. The seminar brought together representatives of the scientific, academic, policymaking and civil society communities. Some of the main ethical and health-care challenges associated to adequate governance and institution-building for the translation of stem cell research results into clinical therapies were illustrated and discussed.
\end{abstract}

Key words: Stem Cell Research, Science and Society, Governance.

- Doutora em Ciências Sociais (University of Sussex), Professora Visitante Estrangeira no Programa de Pós- 


\section{Introdução}

$\mathrm{O}$ presente artigo apresenta os principais resultados do seminário "As Pesquisas e Terapias com Células-Tronco - o Estado da Arte Internacional e no Brasil", realizado no Instituto de Economia da Universidade Federal do Rio de Janeiro (IE-UFRJ), no marco do Programa de Pós-graduação em Políticas Públicas, Estratégias e Desenvolvimento (PPED) e do Grupo de Economia da Inovação, no dia 13 de junho de 2011. O seminário ocorreu no âmbito do projeto de pesquisa: “Desenvolvimento de Capacidades para a Governança: Visões Sociais e o Debate sobre Células-Tronco no Brasil" (Processo N: 470938/2009 9), financiado pelo Edital CNPq Universal 2009. O objetivo principal do projeto é analisar a evolução do papel das percepções sociais, o comportamento institucional e as crenças subjacentes, tanto em relação à inovação, quanto às políticas de regulação para a pesquisa com células-tronco e as terapias celulares associadas'.

O seminário reuniu representantes da ciência, da academia, da regulação e da sociedade civil para a discussão de algumas das tendências nacionais e internacionais das pesquisas com células-tronco (PCT), além dos aspectos éticos e regulatórios das terapias celulares associadas no Brasil, os incentivos institucionais para estas pesquisas no país e a relação entre a sociedade civil, a ciência, a medicina e as políticas públicas do campo.

O desenvolvimento das PCT, no âmbito da nova genética, vem acompanhado de riscos e incertezas que colocam em questão os pressupostos ontológicos dos indivíduos, das comunidades e dos estados nacionais sobre a natureza da vida e da vida humana, as relações entre os seres vivos e entre as espécies, a interação entre ciência, medicina e sociedade e a articulação entre ciência e regulação. A nova genética é um tema complexo, pois envolve múltiplas dimensões inter-relacionadas; ela é ao mesmo tempo um campo de conhecimento científico e médico, um vetor de novas terapias e medicinas, uma oportunidade econômica inovadora, um espaço de novas formas e instituições de poder, um locus de produção, disputa e conflitos de significados culturais, políticos e bioéticos, e um fator que contribui à transformação da sociedade. Tendo em vista as incertezas desse novo campo de conhecimentos em rápida expansão e as complexidades envolvidas, se fazem necessárias novas formas de governança nacionais e internacionais que atuem no sentido de negociar conflitos e definir estratégias comuns entre essas dimensões, assim como maximizar os benefícios para a sociedade (ACERO, 2011).

Apesar do caráter globalizado da dinâmica das PCT, baseada em redes transnacionais de pesquisa, de regulamentação e normatividade bioética, de políticas industriais e comerciais, o espaço nacional ainda é central no estabelecimento de mecanismos de governança culturalmente específicos, na definição dos rumos da pesquisa e no desenho de terapias viáveis, na regulação específica, na significação no imaginário público e nas políticas a serem priorizadas. As respostas aos desafios impostos pela nova genética dependem da trajetória histórica de cada nação, das 
estruturas institucionais já estabelecidas nas sociedades nacionais e dos arranjos institucionais constituídos entre os atores sociais para dar conta desses desafios (JASANOFF, 2005).

As políticas públicas definem ou demarcam regras do jogo entre atores sociais e incentivos para a ação dos indivíduos por elas atingidos. As instituições são sistemas de regras sociais - formais e informais ou tácitas - que estruturam o comportamento e a interação dos indivíduos e são por sua vez estruturadas por eles (HODGSON, 2005). Sendo assim, a escolha das instituições adotadas por uma sociedade é uma decisão política duplamente importante, não só pela estrutura de incentivos fornecida por essas instituições, mas também porque as instituições podem moldar a mentalidade e as preferências dos indivíduos (HODGSON, 2005, p. 94). Portanto, as políticas de promoção das PCT, as práticas locais de pesquisa, os arranjos institucionais, a regulamentação e a normatividade bioética são importantes para a definição das direções da PCT e da terapia celular (TC) no país.

As grandes mudanças sociais, bioeconômicas e de sustentabilidade que os novos conhecimentos em nova genética e nas biotecnologias da saúde promovem e revelam, têm sido destacados como uma das 'revoluções' do capitalismo tardio (ex. IRWIN 1995; ROSE,2007). Sua crescente expansão nos e para os países emergentes intervém na lógica do desenvolvimento capitalista local, na estratificação e nos riscos sociais, na inserção global desses países, assim como na formulação de políticas para o engajamento do público, verificando-se cada vez mais a importância da inclusão democrática da sociedade civil (ACERO, 2011), especialmente dos grupos historicamente excluídos dos benefícios do desenvolvimento. O presente artigo se insere nessa discussão (DINIZ 2007, 2009), em especial, ilustrando os novos mecanismos da bioeconomia nos países em desenvolvimento, a partir de um estudo de caso que reflete as conquistas e desafios na área das pesquisas de células-tronco e de terapias celulares no Brasil e das experiências nessa área relatadas pelos participantes no seminário supracitado.

$\mathrm{O}$ artigo se divide em cinco seções principais, incluindo esta introdução. Na seção 2 apresenta-se um resumo da atuação profissional dos participantes do painel e a metodologia do seminário relatado. Em seguida, são contextualizados e expostos os principais assuntos discutidos no seminário. Posteriormente, são apresentados alguns pontos do debate ocorrido entre os participantes. Por fim, procede-se às considerações finais, focando-se os resultados mais relevantes do seminário e em alguns pontos evidenciados sobre as perspectivas da PCT no país.

\section{Participantes e Metodologia do Seminário}

O seminário contou com quatro painelistas, um moderador e uma comentarista, além da contribuição de pessoas da platéia. Os painelistas foram: Stevens Kastrup Rehen, cientista, professor e Diretor Adjunto do Instituto de Ciências Biomédicas da UFRJ, um dos pioneiros na pesquisa com células-tronco embrionárias no Brasil, 
coordenador do Laboratório Nacional de Células-Tronco Embrionárias (LaNCE); Marisa Palacios da Cunha e Melo de Almeida Rego, Coordenadora do Programa de PósGraduação em Bioética, Ética Aplicada e Saúde Coletiva (PPGBIOS/UFRJ/Fundação Oswaldo Cruz), membro da Sociedade Brasileira de Bioética (SBB) e da Comissão Nacional de Ética em Pesquisa (CONEP), professora e pesquisadora do Instituto de Estudos em Saúde Coletiva (IESC-UFRJ); João Ramos Torres de Mello Neto, professor do Instituto de Física da UFRJ e secretário regional da Sociedade Brasileira para o Progresso da Ciência (SBPC); e Liliana Acero (Ph.D. Sussex, 1983), Professora Visitante Estrangeira do Instituto de Economia, do Programa de Políticas Públicas, Estratégias e Desenvolvimento (PPED-IE-UFRJ), pesquisadora do Grupo de Pesquisa em Economia da Inovação do IE, UFRJ e coordenadora do projeto de pesquisa no âmbito do qual o seminário foi idealizado. A comentarista foi Maria Antonieta Leopoldi, professora do Departamento de Ciência Política da UFF, no Programa de Pós-Graduação em Ciência Política da UFF e no Programa de Pós-Graduação em Políticas Publicas, Estratégias e Desenvolvimento (PPED-IE-UFRJ), além de vice-presidente da Retina Brasil, uma ONG de familiares de pacientes e pacientes de doenças degenerativas da retina. $A$ moderação ficou a cargo de Lia Hasenclever, professora do Instituto de Economia da UFRJ, da Pós-Graduação no Programa de Economia Industrial e da Tecnologia (UFRJ) e no Programa de Políticas Públicas, Estratégias e Desenvolvimento (PPED-IE-UFRJ), integrante do Grupo de Economia da Inovação da mesma universidade.

Os painelistas foram orientados previamente a direcionar as suas apresentações para algumas das seguintes perguntas:

1) Quais seriam as atuais tendências internacionais na produção e difusão das pesquisas com células-tronco e das terapias celulares associadas, segundo a sua área de experiência profissional e/ou pessoal? Poderia apontar os fatos mais relevantes? Destacar o que a experiência internacional poderia oferecer de lições para o desenvolvimento da área no Brasil.

2) Quais seriam as atuais tendências brasileiras nas PCT na produção e difusão das pesquisas com células-tronco e das terapias celulares associadas, segundo a sua área de experiência profissional e/ou pessoal? Poderia apontar os fatos mais relevantes? Destacar tendências que a seu ver acelerariam ou melhorariam o desenvolvimento da área no Brasil.

3) Quais são as principais políticas públicas brasileiras que contribuem para o desenvolvimento da área? Quais seriam os principais tipos de lacunas ou ajustes a realizar nessas políticas? A seu ver, existe uma governança suficientemente adequada para a área e para o desenvolvimento de novas e eventuais terapias associadas?

4) Quais são as principais regulamentações brasileiras que contribuem para o desenvolvimento da área? Quais seriam os principais tipos de lacunas ou ajustes a 
realizar na regulamentação brasileira (ex. legal ou bioética ou de controle sanitário) para a área das pesquisas com células-tronco e para o desenvolvimento de novas e eventuais terapias associadas?

5) O Sr./Sra. acha pertinente uma inclusão mais abrangente da sociedade civil nas opiniões e nas informações para a área? Quais tipos de grupos deveriam se incorporar e para quais assuntos? Como e por quais canais poderia se desenvolver e sistematizar o incentivo e a promoção da participação pública?

As apresentações duraram de 20 a 30 minutos e foram seguidas pelas considerações da comentarista, que tiveram a mesma duração. Posteriormente, os participantes tiveram um debate livre, seguido de perguntas e comentários da platéia. A duração do evento foi de três horas e meia.

\section{Contexto das pesquisas com células-tronco e principais assuntos tratados no seminário ${ }^{2}$}

\section{Definição e breve histórico das pesquisas com células-tronco ao nível global}

As células-tronco (CT) de seres humanos, base da pesquisa com células-tronco (PCT) e das terapias celulares (TC), são células capazes de se diferenciar nos tecidos que compõem o corpo humano. Também é uma característica específica das CT a sua capacidade de se autorreplicar, ou seja, a capacidade dessas células em gerar cópias idênticas de si mesmas. Essas duas características têm convertido atualmente as células-tronco em objeto de importantes pesquisas a nível global, para uma ampla gama de aplicações (ACERO,2011).

Existem três tipos principais de células-tronco, que surgem de diferentes fontes: as células tronco adultas - CTA, as células tronco embrionárias- CTE e as de pluripotência induzida-iPS. As células-tronco adultas são encontradas no organismo já desenvolvido, ou seja, passado o seu estágio embrionário. Essas células são encontradas nos tecidos e órgãos humanos e são multipotentes, ou seja, possuem capacidade de gerar um conjunto limitado de células do corpo. As células-tronco embrionárias são células pluripotentes, ou seja, têm a capacidade de se transformar em praticamente qualquer célula do corpo, com exceção da placenta, e são encontradas somente no estagio inicial dos embriões. As células de pluripotência induzida são células somáticas adultas reprogramadas geneticamente para se converter em células-tronco pluripotentes.

As células-tronco podem ser utilizadas em diversos tipos de pesquisa. Na pesquisa básica, o conhecimento sobre as CT permite conhecer mais profundamente o processo do desenvolvimento humano e as suas eventuais anormalidades. As doenças humanas podem ser estudadas em modelos animais baseados em $\mathrm{CT}$, incorporando aos animais genes humanos mutantes e responsáveis por determinadas doenças, 
para entender melhor funções e processos das mesmas. Também se utilizam CT em estudos de farmacologia e testes toxicológicos, permitindo que novas drogas sejam testadas em células humanas específicas e diferenciadas. Outra aplicação das $C T$, mais polêmica, é na terapia gênica, onde elas são utilizadas como vetores na modificação genética de outras células do corpo humano ${ }^{3}$ (MONTEIRO \& DANTAS, 2008). A aplicação terapêutica mais desenvolvida das CT é a produção de preparados e linhagens específicas para transplantes, visando a produção de populações puras e saudáveis de tipos celulares específicos, que possam ser utilizadas na reparação de tecidos doentes ou lesados. Por exemplo, células pancreáticas para a produção de insulina e células direcionadas ao tratamento de alguns tipos de câncer (ACERO, 2011).

As PCT começaram com células-tronco adultas, a partir da observação dos efeitos regenerativos das células da medula óssea. $O$ interesse nas pesquisas que resultaram eventualmente no desenvolvimento dos transplantes da medula óssea se originou na preocupação científica com os efeitos da radiação na Segunda Guerra Mundial. As primeiras tentativas de transplantes - ainda que infrutíferas- datam de 1939, quando Osgood et.al.(1939) injetaram alguns milímetros de medula óssea em pacientes com anemia aplástica. Desde então, pesquisas com animais avançaram em varias direções, e já no final dos anos 50, vários grupos de cientistas tentaram explorar conceitos desenvolvidos nas pesquisas pré-clinicas para curar o câncer humano, transplantando medula óssea após altas doses de quimioterapia e radiação (UKSCl, 2005). No ano de 1957, Donnall Thomas - que em 1991 iria ganhar o Premio Nobel- estandardizou a coleta e infusão de CTA humanas hematopoiéticas da medula óssea (THOMAS ET. AL., 1957).

Os primeiros intentos posteriores foram pouco produtivos, devido à reação do sistema imunológico dos pacientes pela infusão de tecidos estranhos, um fenômeno conhecido como doença enxerto contra hospedeiro ('graft versus host disease'). Passouse mais de uma década até que os avanços na compatibilização de tecidos tornassem os transplantes de medula óssea adequados aos tecidos dos pacientes. Em 1968, se realizou o primeiro transplante de medula óssea bem sucedido, no tratamento de dois irmãos com uma severa imunodeficiência combinada. A partir daí, verifica-se um alto crescimento global do número dos transplantes de medula óssea (ACERO, 2012).

Em 1981, se produz a primeira linhagem de células tronco desenvolvidas de camundongos. Nos anos de 1999 e de 2000, os cientistas descobriram que a manipulação dos tecidos de camundongos adultos poderia produzir diferentes tipos de tecidos (UKSCl, 2005). Isso significou que células tronco da medula óssea podiam produzir células nervosas ou do fígado, e células tronco do cérebro também podiam produzir outros tipos de células. Estas descobertas foram interessantes para a área de PCT, porque traziam a promessa de um maior controle sobre a diferenciação e proliferação das CT. Além das terapias da medula óssea, os preparados de CTA têm sido utilizados também em humanos, de modo bem sucedido, para transplantes de córnea, na terapia celular para a reparação de cartilagem, no desenvolvimento de 
tecidos da pele ('skin-grafting') e no protocolo Edmonton para o transplante de células do pâncreas de cadáveres (ACERO, 2012).

Outra fonte de CTA é o sangue do cordão umbilical e da placenta. Em 1978 foram descobertas as células-tronco no sangue do cordão humano. O interesse clínico nessas células desenvolveu-se desde 1988, quando foram utilizadas com sucesso em um transplante para o tratamento da anemia de Falconi. Desde os finais dos anos 1980, esses transplantes também têm sido usados no tratamento de outras doenças raras com base em várias deficiências imunológicas (ACERO, 2012).

As linhagens de células-tronco embrionárias, por sua vez, começaram a ser pesquisadas no fim dos anos 1980. Em 1988, se desenvolveu a primeira linhagem de CTE de camundongos e em 1995, a primeira linhagem de um primata. Mas foi a clonagem da ovelha Dolly, em 1997, pelo Prof. Ian Wilmut, do Instituto Roslin, em Edimburgo, pelo uso da técnica de substituição de núcleo celular de uma célula somática adulta pelo de uma célula tronco embrionária (SCNT) - a clonagem terapêutica - que revolucionou esta área. Na atualidade já se utiliza a clonagem terapêutica de forma comercial e para produzir: gado, cavalos, ovelhas, camundongos, cabras, porcos, gatos e cachorros, entre outros animais (ACERO, 2012).

No ano de 1998, o cientista James Thomson da Universidade de Wisconsin nos EUA (THOMSON ET.AL., 1998), isolou células da massa interna de blastocistos humanos embriões desenvolvidos até o quinto dia da gestação - e desenvolveu as primeiras cinco linhagens de CTE humanas. Sua equipe cultivou as linhagens por cinco meses sem diferenciação e após induziram as linhagens a se diferenciar nas principais três camadas embrionárias; e provaram que as linhagens podiam permanecer congeladas sem nenhum dano aparente às suas capacidades de multiplicação. No mesmo ano, o cientista Paul Gearhart e a sua equipe, da Universidade John Hopkins (GEARHART, 1998), também nos EUA, derivou e cultivou pela primeira vez células germinativas humanas de células fetais do tecido das gônadas de fetos abortados. Ou seja, células pluripotentes foram desenvolvidas das duas fontes num período semelhante.

Mais recentemente, em 2007, cientistas japoneses conseguiram reprogramar CTA de fibroblastos de camundongos adultos em um outro tipo de células pluripotentes - denominadas induced pluripotent stem cells (iPS) -, utilizando um retrovírus para ativar quatro diferentes fatores endógenos de pluripotencia em células somáticas adultas (Takahashi et al., 2007). O processo de diferenciação dessas células se desenvolve "rebobinando" as CTA para um momento anterior; as células somáticas adultas revertem a um estado semelhante ao das CTE. As iPS são virtualmente idênticas às verdadeiras $C T E$, pois também são capazes de transformar-se em um organismo em completo funcionamento. O desenvolvimento de iPS ainda é um processo em estágio inicial, apesar dos avanços registrados em pesquisas envolvendo animais. Presenciamos também o início dos ensaios clínicos com iPS em humanos, em geral com poucos pacientes e para testar eficácia. Por exemplo, neurônios foram desenvolvidos desde células iPS para o tratamento da esquizofrenia por parte de 
pesquisadores brasileiros (Paulsen. et.al., 2011) e utilizadas para ensaios clínicos de fase I. Espera-se que o desenvolvimento das iPS humanas, no futuro, possa vir a revolucionar ainda mais a medicina regenerativa, por meio de uma derivação mais simples de CT específicas para a pesquisa e a clínica, com menor potencial de conflitos éticos e com o fim último de lograr a materialização da medicina personalizada, já que as própria células do paciente dariam origem ao tecido terapêutico (ACERO, 2012).

\section{Algumas tendências internacionais na pesquisa e na difusão das células-tronco}

No Seminário, a respeito da evolução das PCT em geral, o professor Stevens Rehen destacou que o objetivo sempre presente nesse campo foi o da reabilitação e expansão das capacidades humanas, através do alto poder regenerativo das CTE e das iPS. O cientista explicou ainda que a tecnologia de isolamento e multiplicação das CTE é relativamente nova ao nível global, com pouco mais de uma década, necessitando ainda de tempo para o amadurecimento, apesar de os ensaios clínicos em seres humanos já terem começado em alguns países.

O professor citou brevemente o caso de três empresas estrangeiras que perseguem o desenvolvimento de terapias com CTE, com possibilidades de comercialização futura. As três empresas (Geron, Viacyte e Life Technologies) estão localizadas na Califórnia-EUA, sendo que a primeira estaria trabalhando com uma linhagem de CTE para o tratamento de lesões da medula espinhal, a segunda, com células iPS para o tratamento da diabetes mellitus, e a terceira, com CTE para o tratamento da esclerose lateral amiotrófica 4 .

O secretário regional da SBPC, João de Mello Neto direcionou sua exposição ao entendimento público da ciência, tratando da relação entre ciência e sociedade no mundo contemporâneo, em especial, em relação à reprodução assistida, ao papel social dos cientistas e às mudanças históricas no imaginário social sobre eles. Ele afirmou que os trabalhos dos cientistas muitas vezes aparecem ao nível social como opacos, inacessíveis e muitas vezes destituídos de um propósito socialmente aceitável.

Observando as tendências em algumas sociedades democráticas, em especial na Europa, o expositor relatou uma perda de confiança do público nas autoridades, políticos e cientistas. A imposição de políticas públicas definidas por especialistas, com pouca participação da população, tem sido amplamente rejeitada. Colaboram para isso eventos negativos associados, por exemplo, à síndrome da vaca louca, à questão nuclear e à segurança alimentar dos transgênicos. Tal percepção tem levado esses países a uma estratégia de engajamento do público no processo de elaboração de políticas públicas, em vez de continuar com uma visão do público como recipiente passivo das decisões governamentais. Tais estratégias - por exemplo, as experiências no Reino Unido - supõem que essa participação pública trará muitos benefícios, mas a sua eficácia ainda não teria sido comprovada. 
Com referência as questões éticas envolvidas na PCTE, Mello Neto comentou a influência dos vários tipos de visões sociais para caracterizar o embrião humano: como ser humano completo ou tornando-se gradualmente um ser humano completo, entre outras, e argumentou sobre o papel da Ciência na definição da questão ética. Ele analisou a relatividade histórica de alguns argumentos públicos sobre Ciência, comparando, por exemplo, os argumentos usados há trinta e três anos para descrever o nascimento do primeiro bebe por reprodução assistida in-vitro (Louise Brown) em 1978, com aqueles utilizados atualmente sobre a PCTE. Segundo o pesquisador, muitas pessoas ficaram horrorizadas com a situação, questionando a normalidade de um ser humano gerado por esse meio. Apesar disso, ele concluiu que hoje já existiriam mais de um milhão de bebês nascidos por meio dessa técnica, o que fez com que aqueles medos e especulações de antes parecessem absurdos.

A professora Liliana Acero comentou sobre os desafios da governança global das biociências, que precisa ter em conta as transformações e as questões que surgem contemporaneamente, entre elas: o reordenamento ontológico que acontece entre natureza e cultura; os novos diálogos entre Ciência e Sociedade, de formas 'top-down' e 'bottom up'; a cidadania biopolítica - o autogoverno do self e do corpo - ; a 'política da vida em si mesma', onde o que muda é a manipulação da própria vida; e as novas formações coletivas de criação de sentido - as epistemologias cívicas; assim como as novas articulações institucionais para a gestão dos riscos e das incertezas. Segundo Gottweiss et al. (2009), autor citado pela pesquisadora, as articulações entre os níveis científicos, tecnológicos, econômico-sociais, éticos e institucionais nas biociências e biotecnologias, ainda ao nível global produzem mapas complexos, confusos e incompletos que precisam se esclarecer para o desenvolvimento de uma governabilidade global da maior importância nesta área.

A professora Liliana Acero também mostrou a localização e distribuição de pesquisas com PCT e com PCTE ao nível global, assim como a flexibilidade da sua regulamentação ao redor do mundo (ACERO, 2012). Entre os países e regiões com maior concentração de centros de pesquisa, figuram: os EUA, a quase totalidade da Europa, o Canadá, a Austrália, a costa do Pacífico na Ásia - em especial, China, Coréia do Sul, Cingapura e Japão -, além da Índia. Em menor proporção, há alguns focos de PCT na África do Sul, na América Latina - principalmente no México, Brasil e Argentina - e no Oriente Médio - principalmente em Israel e nos Emirados Árabes Unidos. Observa-se uma significativa falta de atividade nesta área na África em geral, e em muitos países da América Latina.

Sobre o nível de restrição às pesquisas com $\mathrm{CTE}$, a profesora Acero identificou como os países mais permissivos ${ }^{5}$ : a Suécia, o Reino Unido, a Bélgica, a Austrália, o Japão, a Cingapura, a Coréia do Sul, a China, a Índia e Israel. Todos esses países aceitam a clonagem terapêutica pela técnica SCNT, para a criação de embriões específicos para pesquisa. Dentre os países com regulamentação mais conservadora, que proíbem ou colocam altas restrições à PCTE, encontram-se: a Áustria, a Polônia, a República Checa 
e a Alemanha. Em um nível de regulamentação intermediário, figuram: os EUA, o Brasil, a Rússia, a Espanha, Portugal, a França, a Suíça, a Irlanda, a Noruega, a Finlândia, a Holanda, a Grécia, a Romênia, a Geórgia, e a África do Sul, entre outros. Esses países, em geral, permitem apenas as pesquisas com CT de embriões excedentes da fertilização assistida.

Maria Antonieta Leopoldi, em seus comentários, enfatizou a grande transformação ocorrida nas últimas duas décadas na Ciência e na Sociedade e a ampliação da produção, da divulgação e do acesso à informação científica, fato constatado inclusive nas apresentações dos painelistas. Tais tendências contribuíram, por exemplo, a ampliar fortemente a comunicação entre os pacientes, para o bem ou para o mal, porque pessoas mal-intencionadas também se utilizaram dessas informações. Diante de tais transformações e baseando-se na sua experiência como acadêmica e representante de uma associação de pacientes, a comentarista destacou a grande importância de se estabelecer vínculos internacionais sólidos e de haver redes de contatos entre governos, cientistas e associações da sociedade civil na área. Leopoldi enfatizou, no entanto, que essas redes de ação coletiva só estão bem estabelecidas nos países desenvolvidos. Para exemplificar esta afirmação, foi citado o caso da Stem Cell Coalition, uma coalizão de ONGs, associações de cientistas, médicos e de pacientes, entre outros, que emergiu nos EUA, nos últimos anos, com grande capacidade de mobilização de políticos e da sociedade, de financiamento e de captação de recursos. A Prof. Acero também citou os casos do Canadá e da Inglaterra, onde as próprias associações de pacientes financiam pesquisas.

\section{Algumas tendências do desenvolvimento da PCT no Brasil}

A PCT, no Brasil, começou nos arredores do ano 1999, na USP, com células adultas e financiamento público. Desde então, vem se expandindo de forma consistente, com desenvolvimentos nacionais, em alguns temas, próximos à fronteira internacional, ainda que em grupos com menos recursos econômicos. De 2002 a 2009, foram financiados pelo Departamento de Ciência e Tecnologia do Ministério da Saúde 2.747 projetos em PCT eTC (MINISTÉRIO DA SAÚDE, 2009). Em 2005, os Ministérios de Ciência e Tecnologia e de Saúde iniciaram um programa conjunto, para o ensaio clínico de terapias celulares cardíacas. O Estudo Multicêntrico Randomizado de Terapia Celular em Cardiopatias (EMRTCC), com células tronco adultas (Fases II e III), foi projetado para atender 1.200 pacientes e 40 instituições em diferentes Estados. Posteriormente, um número um pouco menor de pacientes foi recrutado. Também no ano de 2005, o Laboratório de Genética Molecular da USP produziu as primeiras linhagens locais de CTE (ACERO, 2011).

Entre 2005 e 2008, as PCTE continuaram ocorrendo, mas sob incerteza jurídica, já que o artigo da Lei de Biossegurança que permitia a pesquisa e a terapia a partir de embriões excedentes da fertilização assistida, teve sua constitucionalidade ques- 
tionada, vindo a ser declarado constitucional pelo Supremo Tribunal de Federal somente em 2008 (ACERO, 2010; 2011). Neste mesmo ano, o Stevens Rehen, pesquisador do Laboratório de Neurogênese e Diferenciação Celular (LANDIC-UFRJ), criou a primeira linha celular brasileira de células pluripotentes induzidas (IPs).

Em 2009, o Ministério da Saúde, em colaboração com o Ministério da Ciência e Tecnologia, criou a Rede Nacional de Terapia Celular (RNCT), formada por 8 Centros de Terapia Celular (CTC), por 52 laboratórios selecionados e 49 projetos de pesquisa. A proposta da Rede é aumentar a integração entre pesquisadores brasileiros e facilitar a troca local de informações. ${ }^{6}$ Em 2009, o Laboratório Nacional de Células-Tronco Embrionárias da UFRJ inaugurou o primeiro banco brasileiro de linhagens de CTE e iPS, para a criação e distribuição pública dessas células para estudos e pesquisas clínicas. Em 2011, foram realizados no Brasil vários testes locais de medicamentos e drogas com CT, através de ensaios clínicos fase I e II com CTA em pacientes com Acidente Vascular Cerebral, diabetes, problemas de cartilagem, olhos (córnea), entre outros. Neste ano também se inaugurou no país um grande fundo de capital de risco para as biociências e biotecnologias, o fundo Burril Brasil I (ACERO, 2012).

A professora Liliana Acero, após expor esse breve histórico da PCT no Brasil, também descreveu as principais tendências econômicas e sociais da área no país, baseando-se em constatações da pesquisa que coordena para o CNPq, publicadas no livro Pesquisas e Terapias com Células-Tronco: governança, visões sociais e o debate no Brasil. (ACERO, 2011) Sobre os grupos de pesquisa que tratam de células-tronco e terapia celular no país, tendo por referência o ano de 2008 , foi estimada a existência de 2.843 grupos, baseando-se em uma análise do diretório de grupos de pesquisa do $\mathrm{CNPQ}^{7}$. O número de pesquisadores que trabalham nessas áreas foi estimado em 1.703, sendo a grande maioria com nível de doutorado ( $85.49 \%$ deles em PCT e 90.58\% em TC) (ACERO, 2011).

Entrevistas feitas no âmbito do projeto de pesquisa mencionado, com pesquisadores da área, formuladores de políticas públicas e representantes da sociedade civil (totalizando 30 pessoas), revelaram que a maioria dos entrevistados considera o Brasil numa posição intermediária de atualização - nível 3 em um ranking de 1 a 5 com relação à PCT global (ACERO, 2012).

Tratando das tendências nacionais ao nível institucional, Stevens Rehen apresentou a experiência do Laboratório Nacional de Células-Tronco Embrionárias (LaNCE), por ele dirigido. O pesquisador explicou que, antes da fundação do laboratório, promoveu um encontro nacional sobre $C T E$, onde os principais desafios constatados para a pesquisa na área foram: a falta de massa crítica de pesquisadores no campo no Brasil e os altos custos desse tipo de pesquisa, inclusive com a necessidade de importação de grande parte dos materiais necessários ao trabalho. A partir da constatação desses desafios, traçou-se uma estratégia na qual o novo laboratório, criado no final do ano 2009, buscaria gerar antes de tudo uma plataforma para a pesquisa em CTE e iPS, formando recursos humanos na área e promovendo inovações tecnológicas para a redução dos 
custos e da dependência de materiais estrangeiros nas atividades. Essa estratégia gerou resultados importantes, como a especialização de vários pesquisadores no campo das CTE e das iPS, e o desenvolvimento de um novo processo e três novos produtos ${ }^{8}$, que reduziram o custo dessas pesquisas no país. Incrementou-se a divulgação da pesquisa, através de várias publicações e vídeos científicos e não-científicos e dos protocolos de pesquisa empregados no local, todos eles accessíveis no site do laboratório. Através dessa estrutura, o LaNCE passou a avançar nas pesquisas em CTE e vem trabalhando com linhagens de iPS testadas no tratamento de pacientes de esquizofrenia.

Comentando sobre o "espírito público" de abertura da pesquisa e das informações no caso do laboratório LaNCE, a professora Maria Antonieta Leopoldi ressaltou a importância desse comportamento, mas destacou que ele deve ser reavaliado quando se forma uma rede com atores internacionais, "para os quais o segredo é a alma da pesquisa".

A Professora Liliana Acero mencionou como desafios à gestão pública das PCT no Brasil, o desenvolvimento de políticas voltadas a incluir e informar aos diferentes públicos, bem como a promoção de ações públicas sistemáticas na provisão de informações fundamentadas à mídia, segundo manifestado pela amostra entrevistada no projeto de pesquisa que coordena para o CNPq. Verificou-se que, apesar de $70 \%$ dos entrevistados possuírem alguma confiança no progresso da ciência nas PCT, metade dos formuladores de políticas e dos representantes da sociedade civil acha o discurso científico no país hermético ou contraditório 9 . Além disso, 63,3\% dos entrevistados considera pouco satisfatória a divulgação de informações sobre a PCT na mídia (ACERO, 2012).

Nos seus comentários, Maria Antonieta Leopoldi tratou também de outros desafios para as PCT no Brasil. No financiamento das pesquisas, a professora mencionou: a falta de uma instituição equivalente ao National Health Institute americano no país, para direcionar recursos a projetos de interesse nacional na saúde; a falta de uma integração forte entre universidades e empresas, que possibilitaria o financiamento privado das pesquisas, uma vez comprovada sua viabilidade; além da escassez de fundos de capital de risco para pequenas empresas de base tecnológica no país. No Brasil, tem prevalecido o financiamento estatal, mas a participante considera que, "é necessário olhar para outras áreas que não o Estado", inclusive observando as alternativas tomadas em sociedades com uma forte visão pública de saúde, como a Inglaterra e o Canadá, onde as associações de pacientes têm colaborado no financiamento de pesquisas de seu interesse.

\section{Regulamentação e Normatividade Bioética: arcabouço institucional para as políticas de PCT}

O Brasil teve um processo de formação da sua legislação interrupto e complexo em questões pertinentes à PCT. A normatividade atual permanece incompleta, 
por momentos é inespecífica e relativamente fragmentada. Não existe qualquer agência pública, centralizada, semi-centralizada ou independente, especializada na governança da PCT, apesar de haver uma rede de cientistas e médicos muito ativa, a Rede Brasileira de Terapia Celular, e o papel importante exercido pela Agência de Vigilância Sanitária (Anvisa) na regulamentação de algumas práticas de licença, controle e comercialização.

A professora Liliana Acero apresentou um breve histórico da legislação referente, direta ou indiretamente, às PCT no país. A princípio, entre 1999 e 2005, as práticas eram regidas por princípios gerais de direitos civis estabelecidos na Constituição de 1988, juntamente com as regras e Códigos de Prática das Associações Médicas, das Clínicas de Fertilização Assistida e do Conselho Federal de Medicina, além da normatividade da Anvisa. Do ponto de vista jurídico, a PCT era regida pela Lei de Biossegurança de 1995, cujo Artigo $13^{\circ}$ estabelecia a proibição da "produção, armazenamento ou manipulação de embriões humanos destinados a servir como material biológico disponível" (LEl 8974/95). Também é importante a Lei de Propriedade Intelectual de 1996, a qual proíbe as patentes de células e partes do corpo humano (ACERO, 2010; 2011).

Num segundo momento, correspondente a 2005-2008, a legislação brasileira começa a discutir e regulamentar, aspectos mais polêmicos deste tipo de pesquisa. Em particular o da utilização de CTE, através da nova Lei de Biossegurança (Lei 11.105/2005), no artigo $5^{\circ}$, que permitiu a pesquisa e terapia a partir de embriões excedentes da fertilização assistida, inviáveis ou viáveis, no caso de terem sido congelados há três anos ou mais. Esse artigo teve sua constitucionalidade questionada pela Ação Direta de Inconstitucionalidade 3510, baseada na tese de que a vida humana aconteceria no momento da fecundação. No entanto, foi julgado constitucional pelo Supremo Tribunal Federal, em 2008, após uma longa controvérsia pública e com a realização da primeira Audiência Pública da história do STF (ACERO, 2010).

Outras políticas importantes para o campo foram mencionadas pela Prof. Acero, entre elas: a Lei de Inovação (Lei 10.973/2004), que regulamenta as relações entre Universidades, Instituições de Pesquisa e Empresas e pode influenciar as formas de comercialização das eventuais terapias celulares; o Acordo TRIPS (1995), que equaliza internacionalmente as legislações de propriedade intelectual, incluindo as patentes de terapias celulares; e a Lei do Bem (2005), que consolida a concessão de incentivos fiscais e subvenções econômicas para contratações de mestres e doutores nas empresas com P\&D de produtos inovadores.

A professora Marisa Palácios centrou sua exposição nas principais regulamentações brasileiras do tipo ético que regem as pesquisas e ensaios clínicos com seres humanos, e os tipos de lacunas ou ajustes a realizar nelas para a PCT e as terapias associadas. Dividiu sua apresentação entre os seguintes pontos: o sistema de regulação ética; os aspectos operacionais do sub-sistema constituído por Comitês (locais) de Ética em Pesquisa (CEP) e pela Comissão Nacional de Ética em Pesquisa (CONEP); a Lei de Biossegurança; e a regulamentação da Anvisa. 
No primeiro ponto, após descrever os elementos do sistema ${ }^{10}$, a professora Marisa Palácios analisou os seus fluxos no nível contextual e os principais pressupostos em que se assenta: sua finalidade descrita como a máxima proteção dos sujeitos de pesquisa; os seus princípios norteadores: o respeito às pessoas e a autonomia; o balanço positivo entre riscos e benefícios; a garantia de que todo possível malefício será evitado, reduzido ou remediado (tratado); a justiça, ou seja, o pressuposto da construção de consensos públicos provisórios; e a eqüidade, ou seja, garantir que os interesses dos que têm menos possam ser expressos e respeitados.

Tratando do funcionamento do sistema CEP-Conep ${ }^{11}$, a professora explicou que as pesquisas avaliadas são divididas em três grupos: Grupo 1 - Área temática Especial; Grupo 2 - Medicamentos; e Grupo 3 - Demais Projetos. As áreas temáticas foram constituídas para que se pudessem estudar melhor cada uma delas e estabelecer normas específicas para os protocolos serem avaliados pelos CEP e também para o acompanhamento dos projetos de pesquisa por esses comitês. A professora comentou que se condiciona ao mínimo necessário o fluxo de projetos para a avaliação central da Conep, com a exceção de projetos que envolvam questões estratégicas, como populações indígenas, genética e reprodução humana.

Sobre os desafios encontrados nos processos de avaliação de protocolos de pesquisa pelos CEP, Palácios destacou: a vulnerabilidade dos sujeitos de pesquisa, principalmente em casos onde ainda não existem terapias viáveis para esses sujeitos, o que os torna favoráveis a qualquer esforço de pesquisa; a dificuldade no treinamento dos membros dos comitês, para que dominem as ferramentas necessárias a uma avaliação adequada; os conflitos de interesse presentes no contexto acadêmico, onde a realização de uma pesquisa é também um fator de prestígio para os pesquisadores e a instituição de pesquisa; a necessidade de agilizar o sistema geral e melhorar o acompanhamento das pesquisas desde os CEPs; e a inclusão de outros atores sociais interessados na pesquisa, como os usuários dos serviços públicos.

Após isso, a professora resumiu a principal normatividade da Anvisa que reflete na área (ANVISA ${ }^{12}$, e colocou que, segundo os dados obtidos do SisEmbrio ${ }^{13}$ e compilados até Janeiro de 2011, mais de 82.000 embriões estão congelados nas clínicas de reprodução humana assistida e que 2.273 embriões já teriam sido doados para PCTE no Brasil. Concluiu que: "a discussão ética se estabelece entre a precaução e a necessidade de continuar investindo em tecnologia para a qualidade de vida, refere-se portanto ao como fazer protegendo os sujeitos das pesquisas. Proteger sem ser paternalista implica em ações que estimulem a emancipação da população - o controle social".

A comentarista Maria Antonieta Leopoldi destacou que a regulação precisa avançar para dar conta de experiências que vem ocorrendo informalmente. Citou o caso dos ensaios clínicos que tem sido feitos muitas vezes nos consultórios médicos em diferentes países, inclusive o Brasil, onde um médico importa um medicamento, droga ou terapia sendo ainda avaliado em ensaios clínicos fase 2 ou 3, e trata o paciente como se fosse um tratamento estabelecido. Leopoldi explica que há 
médicos bem-intencionados e interados das pesquisas internacionais que adotam essa prática, pela impossibilidade no país de uma prática mais formal - pelo fato de não existirem grupos de pesquisa -, e que o problema decorrente maior dessas práticas seria não informar ao paciente de que trata- se apenas de uma experiência. "[Esses medicamentos] não passam pela Anvisa, porque ela não autoriza, mas curam os pacientes". Comentou também, que haveria um outro problema, já que os dados gerados nessas experiências não seriam usados academicamente, embora os médicos tenham experiência de pesquisa.

\section{Participação da sociedade civil}

Os participantes do seminário parecem concordar com a necessidade de uma maior inclusão da sociedade civil nas políticas relativas à PCT e nas políticas de ciência e tecnologia em geral. Tal constatação fica presente na apresentação de Stevens Rehen, que coloca a inclusão como um dos pontos do tripé que sustenta a concepção do LaNCE. O pesquisador e o laboratório possuem várias iniciativas de divulgação de informações científicas junto ao público amplo, desde a apresentação de informações e audiovisuais na mídia até a possibilidade de visitas ao laboratório. Rehen também lançou um livro de divulgação sobre o tema das células tronco, intitulado Células tronco: o que são? Para que servem? (2007).

A divulgação da informação científica também é um interesse do professor João de Mello Neto, enquanto dirigente ativo na SBPC, que publica a Revista Ciência Hoje. Esta busca atrair um público maior para o conhecimento científico, numa linguagem mais acessível, sem que haja, entretanto, perda da qualidade da informação. O professor colocou na sua apresentação exemplos históricos da aproximação entre a ciência e a sociedade.

A participação social também está presente na constatação de Marisa Palácios, de que um dos principais desafios para as políticas de regulação e da ética em pesquisa está na inclusão dos sujeitos das pesquisas na avaliação destas, sem tratá-los como sujeitos de segunda categoria. A professora sugere, por exemplo, criar um fluxo de informações para uma avaliação mais permanente da "satisfação do usuário", com questionários que possam aferir se o sujeito foi avisado, durante a aplicação do consentimento livre e esclarecido, sobre a natureza e as consequências dos procedimentos, bem como as condições que envolvem a adesão do sujeito à instituição e à pesquisa.

Como já apresentado, a professora Liliana Acero, fazendo referência a resultados parciais da pesquisa que coordena para o CNPq, concluiu que é grande a tendência à desinformação publica em relação à PCT no Brasil, constatando a necessidade: 1) do desenvolvimento de políticas públicas voltadas a incluir e informar aos diferentes públicos; 2) da promoção de ações públicas sistemáticas na provisão de informações 'baseadas em evidencias' aos meios de comunicação e; 3) da realização de consultas 
públicas periódicas mais inclusivas dos diferentes grupos de interesse (stakeholders) presentes na sociedade.

Em linha com os outros participantes do seminário, Maria Antonieta Leopoldi também considerou importante reforçar a divulgação científica sobre a área: "sobre o novo papel do cientista na sociedade, [...] eu acho que nós temos que divulgar e tornar mais claro algumas informações que são herméticas, como a questão das células tronco, como a questão da terapia celular, da genética". A comentarista afirmou ainda que a SBPC tem um papel importante, inclusive através dos canais populares de divulgação, da grande mídia: "Explicar o que é o teste clínico, explicar o que é um medicamento autorizado ou não". A comentadora sustentou ainda que o esclarecimento da população através da divulgação da informação e da comunicação na mídia ajudaria significativamente a diminuir a capacidade das instituições religiosas no país de se apropriar das discussões sobre as pesquisas científicas com seres vivos.

\section{Pontos do debate no seminário}

O debate centrou-se em três temas principais em relação à PCT, cada um com a discussão de diferentes subtemas. Os temas foram: 1) a institucionalização das pesquisas no Brasil; 2) o papel das Universidades nessa institucionalização; e 3) a inserção do Brasil no nível internacional.

A respeito da institucionalização da pesquisa, houve uma convergência de posições em relação a que, de algum modo, o Brasil está ainda "engatinhando" em relação a esse ponto, com respeito a "transformar o conhecimento que é gerado no laboratório em algo concreto para a sociedade" (Stevens Rehen). Sobre as formas alternativas de financiamento, se destacou o fato de que nos últimos dois meses foi inaugurado pelo menos um fundo de investimento para as Ciências da Vida no Brasil (BRIDI, 2011), mas afirmou-se que constituiria ainda um grande desafio para a comunidade científica motivar os cientistas para esse tipo de empreendimento, posto que "esse tipo de empreendimento ainda não é valorizado. O que mede a sua qualidade científica é você publicar artigos científicos, que muitas vezes não vão ser nem citados" (Stevens Rehen).

Sobre as parcerias internacionais, se ressaltou que as associações da sociedade civil brasileiras ainda possuem poucas relações internacionais, o que prejudica a obtenção de informação sobre as tendências internacionais das pesquisas. No entanto, haveria bastante conexão internacional ao nível da comunidade científica, mas argumentou-se que existe nesse sentido ainda uma certa desconfiança, porque no passado teria havido muitos casos de cientistas e médicos brasileiros que foram prejudicados em parcerias internacionais, de diferentes maneiras. Assim, enfatizouse a necessidade de formular estratégias de capacitação e treinamento, junto aos cientistas e médicos brasileiros, em propriedade intelectual e formação de parcerias internacionais. 
Discutiu-se também a escassa participação dos grupos de pacientes no financiamento das pesquisas ao nível nacional comparado ao existente ao nível internacional; comentou-se que no Brasil poucos grupos de pacientes procuram uma aproximação maior com os cientistas nesse aspecto, ao nível da PCT, ainda que pareçam interessados nas pesquisas. Salientou-se o papel potencial das ONGs para captar recursos, especialmente de segmentos sociais nacionais de alta renda, para financiar essas pesquisas. Colocou-se que as conexões entre as ONGs interessadas na PCT e na TC foram fortes somente no caso da Audiência Pública para discutir a Ação Direta de Inconstitucionalidade 3510, no ano de 2007. "Se juntaram aí, mas depois começaram a ter rivalidades, pois possuem diferentes interesses, que não se articulam [...] É um problema local, há muita fragmentação" (Liliana Acero).

Em outro momento, debateu-se também o papel que cumprem as pesquisas médicas 'não oficiais', ou seja, realizadas nos consultórios. Uma participante colocou que: "O sistema [de regulamentação] é muito rigoroso com relação a isso. Medicamento que não tem ainda evidências de que funciona em determinadas circunstâncias, os médicos não podem usar para esses tratamentos. Mas o sistema não está fechado para pesquisas. $\mathrm{O}$ que eu acho que não está correto é o sujeito oferecer um medicamento que não está aprovado para um paciente porque ele acha que aquele medicamento é adequado. Há vários exemplos. [...]" (Marisa Palacios). Numa posição alternativa a essa, se coloca que em muitos casos, esses médicos são respaldados por trabalhos de Congressos e teriam plenas condições de fazer um estudo científico, e que seria um desafio promover que essas pessoas façam pesquisa e apresentem os seus projetos a um CEP. Destacou-se que o problema parece ser a necessidade de se preencher protocolos e que isto acaba desanimando o médico, que não quer parar para lidar com burocracias.

Sobre o segundo assunto, o papel das Universidades na institucionalização, enfatizou-se o papel da Lei da Inovação brasileira (Lei 10.973, de 2 de dezembro de 2004). A professora Lia Hasenclever colocou que a grande contribuição da lei seria a institucionalização da participação dos professores nos empreendimentos privados, mas que faltaria ainda a prática das Agências de Inovação das Universidades e instituições de pesquisa em operar essa lei de modo prático para resguardar todos os interesses. Marisa Palácios, numa posição um pouco diferente, destacou que as parcerias de pesquisadores da universidade com o setor privado ainda têm um caráter personalista, enfatizando o caso de algumas pesquisas em saúde onde ainda: "não há nenhum controle institucional. A pesquisa é do pesquisador, aquele pesquisador presta um serviço para a indústria, você não tem uma intermediação da própria instituição" (Marisa Palácios). Maria Antonieta Leopoldi considerou também a necessidade de se desenvolver um equilíbrio entre o controle institucional e o controle do pesquisador. Na discussão deste subtema, colocou-se que a Universidade também teria que ser captadora de recursos e investir, e que quando tenta eximir-se da possibilidade de pensar o financiamento das pesquisas, perde-se o controle institucional. 
Um avanço já existiria, na relação Universidade-Empresa porque já algumas Universidades teriam Agências de Inovação mais fortes, como as da UNICAMP e da UNESP. Outras agências, por um lado, não deixariam o pesquisador sozinho, mas por outro lado, precisariam amadurecer porque ainda teriam um poder muito limitado e poucos empregados. Concluiu-se que o tempo para o desenvolvimento de uma boa gestão dessas agências dependerá da vontade dos dirigentes da universidade em valorizá-las, mas que, historicamente, esse tempo tem sido longo (Lia Hasenclever).

Ainda assim, alguns participantes apontaram que, na Ciência e na Universidade, haveria ainda um forte temor quanto ao mercado, manifestado no argumento da privatização do conhecimento, entre outros, e por ter havido casos (histórias) que influenciaram nesse temor da comunidade científica quanto ao mercado: "É porque houve também um período de 'terra de ninguém', onde cada um fazia da maneira como achava melhor, então ficou essa insegurança, teria que se reverter essa situação [....." (Stevens Rehen)

Com respeito ao terceiro tema, a inserção do Brasil no nível internacional, houve bastante convergência entre os participantes em considerar que o país precisa se preparar mais antes de entrar no campo internacional. Foram oferecidos vários exemplos dos obstáculos nessa direção: da dificuldade de comercialização equitativa dos frutos da inovação local no mercado internacional; da falta de conhecimento dos pesquisadores e especialistas para lidar com as negociações no mercado e da escassa assessoria jurídica existente nas universidades sobre o sistema de patentes; da burocratização das instituições locais que prejudicou o recebimento de royalties do exterior, em um caso mencionado, como ainda, das escassas fontes de recursos para a PCT fora do apoio público. Por exemplo, em relação ao prestígio internacional da Ciência brasileira, comentou-se que: "Uma agência americana abriu financiamento para pesquisadores de outros países. Tentei [fala o cientista] uma parceria, mas o Brasil não era prioridade deles, não havia uma sensibilização da comunidade lá de que os brasileiros seriam capazes de agregar muito conhecimento." (Stevens Rehen)

Neste sentido, também se discutiu o desconhecimento dos pesquisadores nacionais sobre o sistema de patentes, num contexto onde tem que se discutir ainda a questão do que pode ser patenteado nessa área. Seria então difícil atrair investimento que não seja investimento público. A comunidade científica brasileira ainda desconheceria as especificações e os procedimentos em relação a este tema, ainda que, com a Lei da Inovação, as patentes estejam começando a acontecer. Considerouse que, "ainda seria preciso trabalhar bastante o processo de patenteamento no Brasil" (Stevens Rehen).

Outro subtema discutido foi o da necessidade de maiores contatos dos grupos e redes de pacientes brasileiros com pesquisadores e médicos internacionais, vis-à-vis aqueles com pesquisadores nacionais. $O$ argumento principal nesse caso foi aquele de que a informação sobre doenças sem tratamento estaria 'lá fora': "A única maneira de se 
informar é se vincular à rede de relações, e saber onde estão os principais centros médicos" (Maria Antonieta Leopoldi).

Em relação à visibilidade das pesquisas e ensaios clínicos nacionais- o qual poderia facilitar o contato dos grupos de pacientes com a comunidade científica ao nível local, também foi colocado que: "Agora já existe na Organização Mundial da Saúde (OMS) uma iniciativa de colocar todos os ensaios de pesquisa com CT num site. No Brasil não há um registro público específico de ensaios clínicos com células-tronco, assim poderiam ser agregados outros ensaios pequenos, que não ganham dimensão ou visibilidade do jeito como está (Liliana Acero)." ${ }^{\prime 14}$.

O seminário foi fechado com agradecimento aos palestrantes e demais participantes, os quais se manifestaram interessados em ter os resultados do Seminário difundidos através de um artigo acadêmico e serem divulgados nos seus lugares de trabalho.

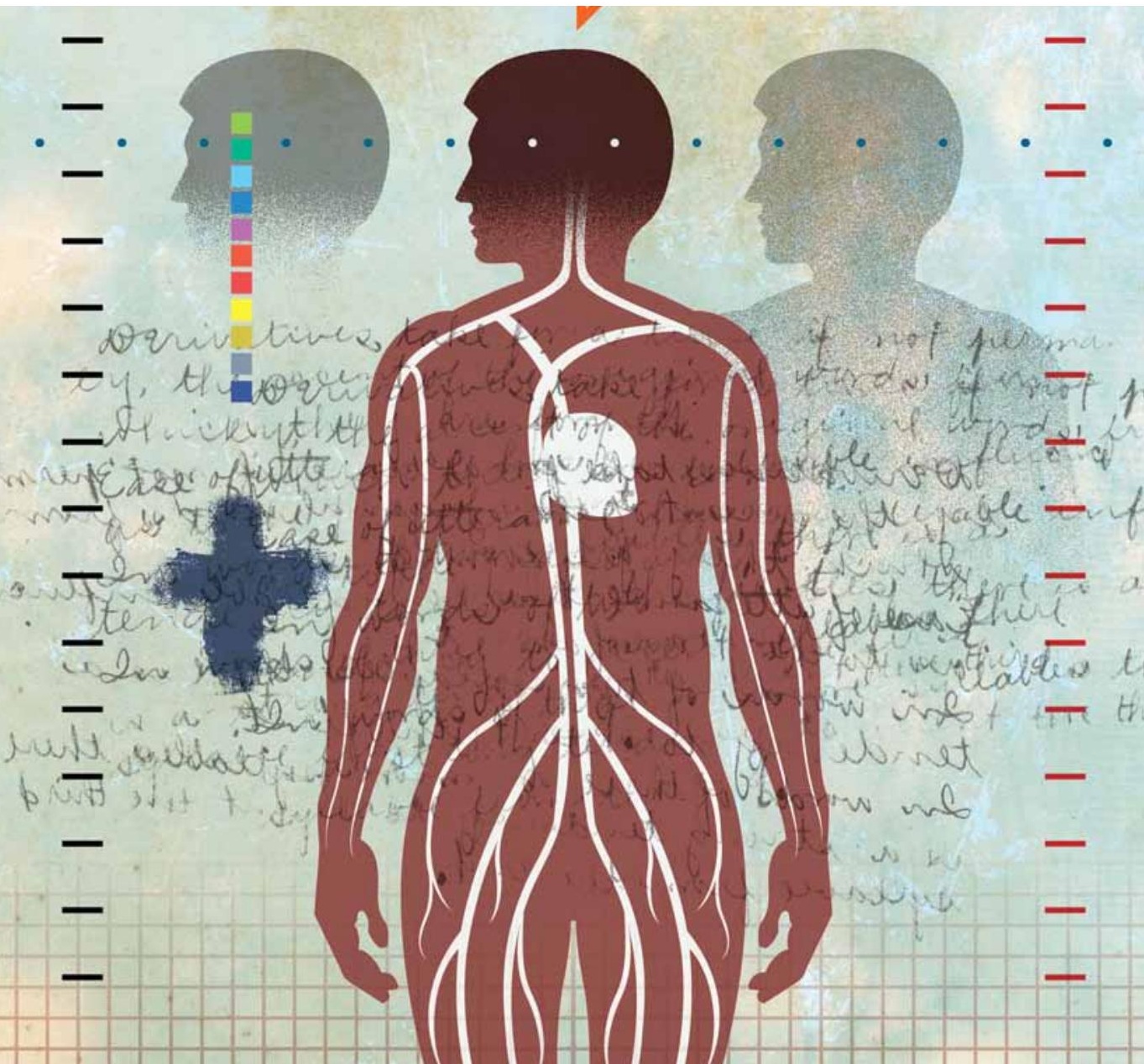




\section{Conclusões}

A pesquisa com células-tronco tem se mostrado um campo altamente dinâmico e promissor desde o seu surgimento, ao nível global e também no país. No entanto, as terapias celulares com CT existentes e eventuais, por envolver muitas dimensões sociais, precisam de novos arranjos institucionais para se desenvolver com rapidez, sem riscos científicos, técnicos, bioéticos e sociais maiores e com sucesso.

O desafio dos países está não só em incentivar e desenvolver as pesquisas no campo, mas também em construir um aparato institucional que permita transformar essas pesquisas em terapias para a população, sem abrir mão da ética e do cuidado que devem envolver terapias revolucionárias aos níveis da saúde, da técnica, da comercialização e de amplas consequências sociais. As PCT precisam então ser encaradas de um ponto de vista geral - aos níveis científicos, médicos, técnicos, econômicos, sociais, participativos e bioéticos - que dê conta da sua complexidade. Nesse contexto, surgem novas relações entre ciência, medicina e sociedade, natureza e cultura, assim como novas fronteiras institucionais nacionais e supranacionais e formas de governança diferentes, e estas precisam ser debatidas continuamente ao nível público, para acompanhar um área de mudanças rápidas e de altas incertezas técnico-científicas e sociais.

O Brasil encontra-se relativamente avançado na PCT, em alguns aspectos, embora ainda necessite aprimorar as suas instituições para alcançar o salto qualitativo que o colocaria mais perto da fronteira internacional e mais perto dos desenvolvimentos de outros países emergentes. Entre os principais desafios constatados no seminário, encontram-se: a necessidade de aproximar a ciência brasileira da sociedade, seja pela divulgação ampla das informações científicas, seja por uma inclusão mais ativa e constante dos sujeitos de pesquisa na regulação, pela aproximação entre as associações da sociedade civil e os pesquisadores, por debates públicos amplos das consequências sociais e éticas das PCT e por um padrão de desenvolvimento baseado na inclusão social; bem como a necessidade de se encontrar formas de financiamento estáveis para a pesquisa e que não dependam exclusivamente do Estado, ampliando as parcerias entre os pesquisadores - e suas organizações - e as empresas, e tornando viável o financiamento das pesquisas por associações de pacientes ou de caridades. É necessário garantir, entretanto, que algumas das novas formas de financiamento não tornem inacessíveis as novas terapias aos grupos menos privilegiados da sociedade, nem alterem os aspectos fundamentais da ética em pesquisa nessa área ou a proteção das populações mais vulneráveis.

O seminário mostrou algumas das vantagens e desvantagens das instituições brasileiras na PCT nacional. No entanto, é possível enxergar que o país tem feito esforços deliberados no aprimoramento das suas instituições e a sua normatividade para o enfrentamento dos desafios que surgem com o avanço da ciência, da tecnologia e da medicina de ponta nas últimas décadas, e que esses esforços se refletem, em certa medida, na área da PCT e das terapias celulares associadas. 


\section{Notas}

1 Agradecemos a equipe do projeto pelas suas contribuições: Lia Hasenclever; Sandra Becker; Helena Klein, Paulo Savaget; e em especial, a Paulo Savaget, pela contribuição na organização do presente Seminário. Para mais informações, consultar o site do projeto: www.govcel.com.br

${ }^{2}$ Vale ressaltar que nem todos os participantes abordaram todos os subtemas, portanto, algumas das subseções adiante não citam as falas de todos os participantes.

3 Um exemplo de terapia gênica relacionada com terapia celular é o uso de CT hematopoiéticas, modificadas geneticamente, para serem resistentes ao vírus do HIV/AIDS.

${ }^{4}$ Constata-se que a Geron é a única entre as três que tinha começado um ensaio clínico aprovado pelo FDA no ano de 2009 para o teste de uma droga em base a CTE e decidiu parar o recrutamento recentemente, em Novembro de 2011, por não ter encontrado grandes progressos nos pacientes. As outras duas empresas ainda estão em fase de testes pré-clínicos. Para mais informações, consultar: http:// www.geron.com; http://www.viacyte.com; http://www.lifetechnologies.com. Acesso em: 03/07/2012.

${ }^{5}$ Fonte: Website "University of Minnesota Medical School". Disponível em: <http://mbbnet.umn.edu/ scmap.html>. Acesso em: 18/08/2012.

${ }^{6}$ Fonte: <http://www.rntc.org.br/>. Acesso em: 12/09/2011.

${ }^{7}$ Usando as seguintes variáveis para a busca: Nome do grupo, Nome da linha de pesquisa, Palavra-chave da linha de pesquisa, Título da produção em CTA e CTE; Palavra-chave da produção. (O total pode estar superestimado, pois um mesmo grupo pode estar incluído nas duas categorias).

${ }^{8} \mathrm{O}$ novo processo refere-se a um novo método de cultivo de culturas de células-tronco, criado a partir de uma parceria com a COPPE/UFRJ, que reduziu significativamente os custos e diminui o tempo do processo. Os novos produtos foram: um meio de cultura para as células iPS, mais barato do que o utilizado anteriormente; uma matriz extracelular para o cultivo de células-tronco; e um software livre e de uso amplo para contagem automática de células-tronco, o ESCC (Embryonic Stem Cell Counter). Para mais informações, ver o site http://www.lance-ufrj.org/

${ }^{9}$ Hermético: de difícil leitura, apresentado com alto nível de especificidade acadêmica. Contraditório: por vezes afirma vantagens demais e por outras o contrário.

${ }^{10}$ Pesquisadores; Sujeitos de pesquisa; Cep - Conep; Instituições de pesquisa; Indústria; Sistema de saúde - assistência; O setor saúde e suas agências reguladoras - MS; Anvisa; ANS; Sistema jurídico.

${ }^{11}$ A Comissão Nacional de Ética em Pesquisa - CONEP é uma comissão do Conselho Nacional de Saúde CNS criada em 1996 com a função de implementar as normas e diretrizes regulamentadoras de pesquisas envolvendo seres humanos, aprovadas pelo Conselho. Tem função consultiva, deliberativa, normativa e educativa, atuando conjuntamente com uma rede de Comitês de Ética em Pesquisa - CEP- organizados nas instituições onde as pesquisas se realizam. Consultar htpp://: http://www.datasus.gov.br/conselho/ comissoes/etica/conep.htm

${ }^{12}$ As resoluções RDC/ANVISA: 190/2003, 29/2008 e 33/2006.

${ }^{13}$ O Sistema Nacional de Produção de Embriões (SisEmbrio) é um sistema desenvolvido pela Anvisa, que tem como objetivo criar um banco de dados sobre a produção de células germinativas (oócitos) e embriões humanos armazenados nos Bancos de Células e Tecidos Germinativos-BCTGs, mais conhecidos como clínicas de Reprodução Humana Assistida.

${ }^{14}$ No ano de 2010 foi criado o Rebec- Registro Brasileiro de Ensaios Clínicos, que registra todos os ensaios clínicos do Brasil ( fase 3) em andamento e em recrutamento no país. Com código aberto (open source), o Rebec é um projeto conjunto do Ministério da Saúde (Decit/MS), Organização Panamericana de Saúde (Opas), Centro Latinoamericano e do Caribe de Informação em Ciências da Saúde (Bireme) e a Fundação Oswaldo Cruz. Desde abril de 2011, o Rebec passa a fazer parte da Plataforma Internacional de Registro de Ensaios Clínicos da Organização Mundial da Saúde (ICTRP - OMS), com a vantagem que assim os registros nacionais atendem às exigências de revistas científicas e órgãos reguladores, por exemplo, do International Committee of Medical Journal Editors (ICMJE). (Consultar htpp:// www.ensaiosclinicos.gov.br Acesso em 17 de Outubro de 2011). 


\section{Referências}

ACERO, L. Desenvolvimento de Capacidades para a Governança: Visões Sociais e o Debate sobre Células-Tronco no Brasil. Relatório Final de Pesquisa MCT/Universal/CNPq. Instituto de Economia, UFRJ, 2012.

ACERO, L. Pesquisas e Terapias com Células-Tronco: Governança, visões sociais e o debate no Brasil. Rio de Janeiro: Ed. E-Papers, 2011.

ACERO, L. Ciência, Políticas Públicas e Inclusão Social: Debates sobre Células-tronco no Brasil e no Reino Unido. DADOS, Rio de Janeiro, vol. 53, n 4, 2010.

BRIDI, C. Burrill \& Company vai investir em ciências da vida no Brasil. Revista Capital Aberto, São Paulo, ano 2 (Especial Private Equity). Disponível em: <http://www.capitalaberto.com.br/ ler_artigo.php?pag=3\&sec=100\&i=3227>. Acesso em: 20/10/2011.

DINIZ, E. (org) O pós-consenso de Washington, tendências e perspectivas: um balanço, in Globalização, Estado e Desenvolvimento: Dilemas do Brasil no novo milenio, FGV Editora, Rio de Janeiro, 2007.

DINIZ, E. Estado, variedades de capitalismo e Desenvolvimento em Países Emergentes, Seminario Internacional INCT/PPED - IE UFRJ,' Promovendo Respostas a Globalização, 3-6 Novembro, 2009.

GEARHART, J. New Potential for Human Embryonic Stem Cells, Science, vol. 282, n.5391, p. 1061-1062, 6 novembro, 1998.

GOTTWEISS, H. ET. AL. The Global Politics of Human Embryonic Stem Cell Science: Rengenerative Medicine in Transition, London: PalgraveMacMillan, 2009.

HODGSON, J. Institutions and Economic Development: Constraining, Enabling and Reconstituting. in Dymski, G. and De Paula, S. Reimagining Growth, Zed Books. 2005

IRWIN, A. Citizen Science: A Study of People, Expertise and Sustainable Development, Londres: Routledge (Environment and Society), 1995.

JASANOFF, Restoring reason: casual narratives and political culture, in Huttter and Power (eds.) Chapter 9, Organizational encounters with risk, Cambridge University Press, 2005.

MINISTÉRIO DA SAÚDE. SUS: 20 anos, células-tronco, gastos do SUS, 2009. Disponível em: www. portalsaude.gov.br. Acesso em: 28/11/2009.

MONTEIRO, A.; DANTAS, M. A pesquisa em células-tronco. Folha de S. Paulo, Rio de Janeiro, 12 maio 2008.

OSGOOD, E. E., et al. Total differential and absolute leakocyte cotnts and sedimentation rates. Archives of Internal Medicine, v. 64, p.105-120, 1939.

PAULSEN, B. et.al. (2011). Altered oxygen metabolism associated to neurogenesis of induced pluripotent stem cells derived from a schizophrenic patient, Cell Transplantation, v. 1, p. 1000-1010, 2011.

ROSE, N . The Politics of Life Itself: Biomedicine, Power, and Subjectivity in the Twenty-First Century, Oxford: Princeton University Press, 2007.

REHEN, S. Células - tronco: o que são? Para que servem? Ed. Vieira e Lent, 2007.

TAKAHASHI, K. et. al. Induction of Pluripotent Stem Cells from Adult Human Fibroblasts by Defined Factors. Cell, vol.131, n,5, p. 861-872, 30 November 2007.

THOMAS, E. et al. Intravenous infusion of bone marrow in patients receiving radiation and chemotherapy. New England Journal of Medicine v. 257, p.491-496, 1957. 
THOMSON, J. A. Embryonic stem cell lines derived from human blastocysts. Science, vol. 282, n.5391, p. 1145-1147, 6 novembro 1998.

UKSCI (UK Stem Cell Initiative). Report and Recommendations. London: Department of Health, 2005.

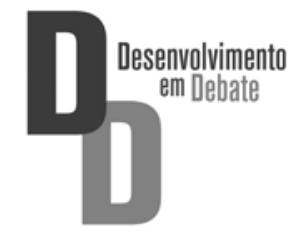

